\title{
Application of Mock-Court as an Interdisciplinary Model for Consolidation of Professional Training of Law Students
}

\section{Sergey Petkov ${ }^{1}$ \\ Viktoriia M. Savishchenko ${ }^{2}$ (I) \\ Bohdana Semenyshyna-Fihol ${ }^{3}$ \\ Tetiana A. Poda ${ }^{4}$ \\ Iryna M. Chaika ${ }^{5}$}

'Alfred Nobel University, Dnipro, Ukraine.

Email:1981phd@gmail.com Tel:+380668047077

${ }^{2}$ Dnipropetrovsk State University of Internal Affairs, Dnipro, Ukraine.

Email:v-savishenko@ukr.netTel:+380667175172

${ }^{9}$ National Academy of State Border Guard Service of Ukraine of Bohdan Khmelnytsky, Khmelnytskyi, Ukraine.

Email:danusy7777@gmail.com Tel: +980978s24578

${ }^{4}$ National Aviation University, Kyiv, Ukraine.

Email:podatetiana@ukr.net Tel:+380688404857

${ }^{5}$ Regional Service Center of the Ministry of the Interior in Kyiv, Kyiv, Ukraine.

Email:ira.semenyshyna1s@gmail.com Tel: +380637680982

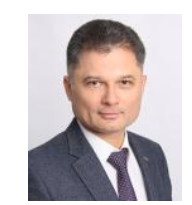

( Corresponding Author)

\begin{abstract}
This study deals with solving the current problem of pedagogy of high school - consolidation of theoretical and practical approaches to ensure the quality of professional training of law students. According to the author, the introduction of simulation modelling technologies in training courses allows enhancing interdisciplinarity in teaching, which is an important way of meeting the dynamic needs of students in close connection of theoretical and practical blocks of professional training of future specialists. The experience of the American Bar Association on the future of legal education has suggested the idea of applying mock-court as interdisciplinary models. Experimental application of mock-court was tested in the courses "Criminal Law" and "Civil Law", which are part of the block of special disciplines of the educational and professional training program in specialty 081 "Law". Mathematical data processing and STATA software were used to analyse the results obtained and to objectively consider the dynamics of changes in personalityorganizational, operational-activity, cognitive-competence, personality-motivational, informationtechnological, linguistic-communicative components. The study showed the effectiveness of the use of mock-court on the development of all components of the readiness of law students for professional socialization. The authors concluded that the application of mock-court in the professional training of future lawyers contributes to feedback increasing students' educational motivation and allows monitoring of changes in student development. This model can be applied to enhance interdisciplinarity in the teaching of other courses of the block of special subjects of professional training of lawyers.
\end{abstract}

Keywords: Simulation modelling technologies, Interdisciplinarity; Mock-court, Professional socialization, Practical approaches, Block of special disciplines, Educational and professional training program, Consolidation of professional training.

Citation | Sergey Petkov; Viktoriia M. Savishchenko; Bohdana Semenyshyna-Fihol; Tetiana A. Poda; Iryna M. Chaika (2020). Application of Mock-Court as an Interdisciplinary Model for Consolidation of Professional Training of Law Students. Journal of Education and e-Learning Research, 7(2): 122-129.

History:

Received: 10 February 2020

Revised: 13 March 2020

Accepted: 16 April 2020

Published: 7 May 2020

Licensed: This work is licensed under a Creative Commons

Attribution 3.0 License (co)

Publisher: Asian Online Journal Publishing Group
Acknowledgement: All authors contributed to the conception and design of the study.

Funding: This study received no specific financial support.

Competing Interests: The authors declare that they have no conflict of interests.

Transparency: The authors confirm that the manuscript is an honest, accurate, and transparent account of the study was reported; that no vital features of the study have been omitted; and that any discrepancies from the features of the study have been omit
study as planned have been explained.

Ethical: This study follows all ethical practices during writing.

\section{Contents}

1. Introduction.

2. Research Methods

3. Results 


\section{Contribution of this paper to the literature}

This study contributes to existing literature by solving the current problem of pedagogy of high school - consolidation of theoretical and practical approaches to ensure the quality of professional training of law students.

\section{Introduction}

The current state and prospects of development of the educational sector both in Ukraine and in the world determine the need to create new and adapt the tried and tested methods of teaching subjects in higher educational institutions in order to provide the economic and social spheres of the state with competitive specialists in accordance with the requirements of the labour market. In order to act at a high level of professionalism in addressing production issues, professionals need to be able to critically analyse information, synthesize knowledge and draw conclusions based on ambiguous information (Tynjälä, Slotte, Nieminen, Lonka, \& Olkinuora, 2006). Therefore, employers are increasingly demanding that high school graduates have the ability to solve complex issues, both in science and in the professional environment (Jacobson \& Wilensky, 2006; Roehler, Fear, \& Herrmann, 1998).

One of the key requirements for quality professional training is the close connection between theoretical knowledge and practical skills of young professionals. This was the conclusion of the American Bar Association (2013). The ABA (2014) when analysing the state of training of students for future professional activity, says that most law schools now offer few practical courses, and call for law schools to increase the practical part so that the educational experience gained by students during the advocacy course prepares them for independent legal practice. In the context of repeated increase in the volume of information and "shift" towards theoretical legal content, which is traditional for the legal education, it is not possible to fulfil this requirement without the introduction of innovative methods in the organization of the educational process in higher educational institutions. At the same time, these practice-oriented methods should not just familiarize, but "immerse" the student in the conditions as close as possible to future professional activity.

Many scholars (for example, Jacob (2015)) believe that an important way to meet the dynamic needs of students is to apply multidisciplinary approaches to the organization of the educational process in higher education institutions in order to ensure close communication between theoretical and practical blocks of professional training of future professionals. Practical and scientific interest in the introduction of interdisciplinarity has been quite active in the last century (Dana \& Sheps, 1968; Jackson, 1959; McCorcle, 1982; Stone, 1969). In the most general interpretation, interdisciplinarity is an educational approach that focuses on more than one subject (Kozakiewicz, 2008). The purpose of interdisciplinary education is to "enhance the ability to work in teams and collaborate among representatives of different professions, thereby enhancing practical training within the subject" (Weinberg \& Harding, 2004). Structured (that is, additive) professional education is a way to focus on particular aspects of the specialty, and interdisciplinary "collaboration" of subjects becomes necessary when focusing on the effectiveness of professional activity. Interdisciplinarity can help solve today's complex problems because it is believed that it is the "multidisciplinary approach that promotes comprehensive understanding" (Newell, 2007). Compared to traditional higher education, which focuses on providing students with structured knowledge across subjects and on the overall development of skills, this type of higher education aims at developing the "border crossing" skills in related disciplines. Knowledge of different disciplines is compared and replaced by integration (Klein, 1990). Integration or synthesis of knowledge is considered a defining feature of interdisciplinarity. Boise Mansilla, Gardner, and Miller (2000) offered the following understanding of interdisciplinarity: "The ability to integrate thinking in two or more subjects to achieve cognitive progress - for example, to explain a phenomenon, solve a problem, or create a product - in ways that would be impossible when applying the means of separate subjects" (p. 219).

The development and implementation of multidisciplinary approaches, interactive combined techniques to ensure the quality of teaching of professional subjects has been at the center of up-to-date research in a number of theorists, teachers and practitioners (Burgess, 1995; Faria \& Dickinson, 1994; Kodotchigova, 2002; Nancarrow et al., 2013; Pometun, 2007; Sisk, 1995). However, the issues of introducing interdisciplinary models into the practice of teaching professional subjects in legal higher educational institutions are insufficiently addressed and need further elaboration.

The objective of this study is to substantiate and experimentally test the effectiveness of applying interdisciplinary models to ensure the quality of professional training for law students.

\section{Research Methods}

The study is of a prolonged nature, conducted using common scientific theoretical, empirical and statistical methods of research and analysis of results according to the task of each stage.

\subsection{Research Design}

The study included four steps: 1) preparatory; 2) organizational; 3) realizational and reflectional; 4) final. Figure 1. Presents the research design. 


\begin{abstract}
Preparatory stage: the study and analysis of theoretical and methodological sources on the problem; substantiation of the reasonability of applying interdisciplinary approaches to educational activities; selection and adaptation of mock-court; development of criterion tools to determine the efficiency of the application mock-court in the training courses: "Criminal Law" and "Civil Law"; selection of diagnostic tools

Organizational stage: creation of general and role scenarios of mock-court for the training courses "Criminal Law"
and "Civil Law"; formation of valid sample; pre-experimental assessment and its analysis; processing od data
obtained
\end{abstract}

Final stage: interpretation of statistical indicators; comparison of the results obtained with those expected; development of recommendations

Figure-1. Research design.

At the preparatory stage, when determining the theoretical and methodological basis of the study, the works of Taylor (2006), Weinstein (1999) attracted our attention, where the scholars analyse educational approaches to professional training of lawyers, claiming that all structurally different educational approaches have long-lasting influences on the course and degree of professional socialization of the specialist. Thus, according to scholars, the methodology of providing educational information and the model of professor-student relations should be regarded as a prerequisite for the creation of a professional culture that will largely shape the future professional. If the professor-student relationship model firmly enshrines the professor's authority through extensive lectures and complete control over student decision-making (knowledge and understanding of educational content through the lens of the professor's vision), such a specialist will be much more passive at the stage of primary professional socialization. Students who have the opportunity to gain additional knowledge on their own (even under the supervision of a professor), additional understanding and experience due to their practical application in real conditions or modelled conditions, take an active position during their primary professional socialization, shorten their adaptation period and have extended career opportunities.

The work of Morse, Nielsen-Pincus, Force, and Wulfhorst (2007) is equally interesting for the fulfilment of the research objectives, where the authors analyse the barriers to implementing multidisciplinary approaches in education and research and ways to overcome them. The development of techniques for the use of interactive technologies for higher education (Artemjeva \& Makeeva, 2007; Bodin, Marty, \& Carron, 2011) is of particular importance for our study. The use of educational games as a way to model the conditional professional environment allows "including" the student in the scientific model of the theory of professional activity (Bellotti et al., 2011). Within the conditionality of the educational game, the student is forced to learn or even make his own patterns of professional actions, to reproduce the optimal variants of professional behaviour, which helps him in understanding the sense of the profession and promotes the formation of his professional competence. However, nowadays, foreign and domestic didactics are moving away from the use of the term "game", which is associated with entertainment and a frivolous attitude towards the accomplishment of tasks, and use the concepts of "simulation", "imitation", etc. (Kichuk, 2005). Imitations are performing some simple known actions that reproduce, imitate any phenomena of surrounding reality. Simulations are specially created learning situations in which participants copy procedures related to the activities of public institutions that exist in real economic, political and cultural life (e.g., court, parliamentary, public hearings, meetings, committee meetings, political debates) etc.) (Kichuk, 2005).

From a large arsenal of interactive, role and business training games, the task of "consolidating" the subject of professional training of law students, in our opinion, corresponds to mock-court introduced in training courses. We rely in our opinion on the study of the works of American scholars (for example, (Arbetman \& O'Brien, 2010; Butcher, Grimes, \& Parker, 2010; Crane, 1999)). To test the hypothesis of the study, training courses "Criminal Law" and "Civil Law" were selected. Work on selecting and adapting mock-court to the educational content of the Criminal Law and Civil Law courses was preceded by familiarization with the practice of organizing and conducting Mock Trial Competitions among law schools in the states of New Hampshire and New Jersey (NHBA's Law Related Education Programm, 2017; The Vincent J. Apruzzese High School, 2019) and other regions.

In order to develop tools to determine the effectiveness of the application of mock-court in the Criminal Law and Civil Law courses, we conducted a student survey after their practical training and an interview of the supervisors of practical training to identify problematic points in training of future lawyers. Despite the variability of the answers and the forms of their expression, our analysis allowed comparing and grouping the information obtained. The results of this work are summarized in Table 1 .

The identified problem blocks quite fully reflect the "bottlenecks" of professional training of law students, which, according to the hypothesis of our study, can be eliminated through the use of multidisciplinary models mock-court. In accordance with the characteristics of the problem blocks, the following components of the readiness of law students for professional socialization and the corresponding criteria for the effectiveness of the use of mock-court in training courses were distinguished: 1) personal-organizational; 2) operational-activity; 3) cognitive-competence; 4) personality-motivational; 5) information-technological; 6) linguistic-communicative. The distinguished criteria for the effectiveness of the use of mock-court in training courses generally characterize the readiness of law students for professional socialization. These components have become a prerequisite for distinguishing the high, sufficient, medium and low levels of readiness of law students for professional socialization. 
Table-1. The main shortcomings in the training of students and the difficulties of passing practical training.

\begin{tabular}{|c|c|c|}
\hline $\begin{array}{l}\text { According to the answers of the } \\
\text { supervisors of practical training }\end{array}$ & According to students' answers & Problem blocks \\
\hline inattention, passivity, infantilism & $\begin{array}{l}\text { difficulty (physical or emotional) of } \\
\text { staying in unusual conditions for a } \\
\text { long time }\end{array}$ & $\begin{array}{l}\text { ability for self-organization and } \\
\text { planning }\end{array}$ \\
\hline $\begin{array}{l}\text { misunderstanding of procedural } \\
\text { features }\end{array}$ & $\begin{array}{l}\text { unclear understanding of how to } \\
\text { properly accomplishing the tasks }\end{array}$ & $\begin{array}{l}\text { ability to identify effective ways to } \\
\text { accomplish tasks }\end{array}$ \\
\hline insufficient theoretical background & lack of real knowledge & $\begin{array}{l}\text { ability to analyse and synthesize } \\
\text { information, to } \\
\text { comprehend it }\end{array}$ \\
\hline lack of initiative, irresponsibility & $\begin{array}{l}\text { fear of doing something wrong, } \\
\text { unwillingness to stand out from the } \\
\text { group }\end{array}$ & ability to make responsible decisions \\
\hline low computer literacy & $\begin{array}{l}\text { difference in the software from the } \\
\text { one the students got used to }\end{array}$ & $\begin{array}{l}\text { ability to make extensive use of } \\
\text { computer skills }\end{array}$ \\
\hline poor literacy in the use of terminology & $\begin{array}{l}\text { complexity of the rules (or lack of } \\
\text { clarity) in the use of terminology }\end{array}$ & $\begin{array}{l}\text { ability to effectively apply linguistic } \\
\text { skills }\end{array}$ \\
\hline
\end{tabular}

In order to determine the levels of development of personality-organizational, operational-activity, cognitivecompetence, personality-motivational, information-technological and linguistic-communicative components of the readiness of law students to professional socialization, different diagnostic methods were used in the study taking into account the structure of the phenomenon under research. Thus, the level of development of the personalityorganizational component of the readiness of future law specialists for professional socialization was determined using the questionnaire "Research on Different Types of Organizational Culture" by Harrison (Lutens, 1999) operational-activity - using the adapted version of the questionnaire by Ivanchenko (2005). Data on the manifestation of the cognitive-competence component of readiness of future lawyers for professional socialization were obtained by testing "Determination of Students' Level of Knowledge and Results of Student Success" (Bandurka \& Skakun, 2002). The level of the development of personality-motivational component of the readiness of future lawyers for professional socialization was determined using Zamfir's method in Rean's modification (Mironova, 2006). The level of the development of information-technological component was determined through a survey "Studying the State of Development of Students' Information and Communication Competencies" (Feshchuk, 2009). Data on the manifestations of the linguistic-communicative component of the readiness of future lawyers for professional socialization were determined by testing "Assessment of Communication and Linguistic Abilities" (Popova, 1997).

At the next stage of the study (organizational), work was done on the creation of a general scenario and "generation" of role scenarios of mock-court for the courses "Criminal Law" and "Civil Law". To do this, we used different materials with the rules of mock-court (Mock Trial Team Rulebook 2014-2015), situational tasks and business games for law students (Boreychuk \& Pelech, 2016; Boreychuk \& Sakhno, 2015).

\subsection{Valid Sampling}

At this stage of the survey, 329 students of the first (bachelor) level of the $2^{\text {nd }}-3^{\text {rd }}$ years of study (Specialty 081 "Law") and 9 lecturers of professional subjects of higher education institutions (Chernihiv State Institute of Law, Social Technologies and Labour, Kherson Branch of Odessa State University of Internal Affairs, Kherson Institute of Economics and Law, Academy of Labour, Social Relations and Tourism (Kyiv). An online validation sample calculator was used to determine the representative sample. For the general population of respondents 338 (95\% confidence probability and 13.98 confidence interval), the valid sample size is 43 persons. The experimental (EG) and control groups (CG) were formed taking into account the specified index of valid sample. The experimental group (EG) consisted of 22 persons and the control group (CG) included 21 persons. The comparative analysis was carried out within existing academic groups by typical programs. In the control group, the practical classes were conducted according to standard methods, and in the experimental group - with the use of mock-court in the courses "Criminal Law" and "Civil Law".

The next step was to diagnose the students of the control and experimental groups using questionnaires and tests specified in the methodological background of the study in order to determine the initial levels of the components of students' readiness for professional socialization. The data obtained during this diagnosis are presented in Table 2.

As we can see, the characteristics of the experimental and control groups are quite comparable in general before the mock-court. Thus, according to the indicators of the personality-organizational component of readiness for professional socialization, the absolute majority of students in the experimental and control groups showed medium $(59.10 \%$ and $57.25 \%$, respectively) and low levels $(22.70 \%$ and $28.50 \%)$. The next largest group is the group with sufficient level of readiness for professional socialization $-13.65 \%$ in the experimental group and $9.50 \%$ in the control group. A similar pattern is observed in the indicators of the readiness for professional socialization in operational-activity and cognitive-competence components see Table 2.

According to the criterion of development of the personal-motivational component of readiness for professional socialization both in the experimental and in the control group, the highest proportion was students with a sufficient level (49.95\% and 52.25\%, respectively). Approximately one third of students showed medium level (31.85\% and $28.75 \%$, respectively). A high level of personal motivation development was determined in students, whose share was less than one tenth of the total number of respondents $(9.10 \%$ in the experimental group and $9.50 \%$ in the control group). The same number of participants demonstrated a low level of readiness for professional socialization by the described component. 
Table-2. Comparative table of readiness of law students for professional socialization (pre-experimental assessment).

\begin{tabular}{|c|c|c|c|}
\hline \multirow[t]{2}{*}{ Components of readiness } & & \multicolumn{2}{|c|}{ Pre-experimental assessmen } \\
\hline & & EG (\%) & CG (\%) \\
\hline \multirow{4}{*}{ Personality-organizational } & High & 4.55 & 4.75 \\
\hline & Sufficient & 13.65 & 9.50 \\
\hline & Medium & 59.10 & 57.25 \\
\hline & Low & 22.70 & 28.50 \\
\hline \multirow{4}{*}{ Operational-activity } & High & 4.55 & 4.75 \\
\hline & Sufficient & 18.25 & 19.00 \\
\hline & Medium & 49.95 & 57.25 \\
\hline & Low & 27.25 & 19.00 \\
\hline \multirow{4}{*}{ Cognitive-competence } & High & 4.55 & 4.75 \\
\hline & Sufficient & 18.25 & 9.50 \\
\hline & Medium & 54.50 & 52.25 \\
\hline & Low & 22.70 & 33.50 \\
\hline \multirow{4}{*}{ Personality-motivational } & High & 9.10 & 9.50 \\
\hline & Sufficient & 49.95 & 52.25 \\
\hline & Medium & 31.85 & 28.75 \\
\hline & Low & 9.10 & 9.50 \\
\hline \multirow{4}{*}{ Information-technological } & High & 9.10 & 9.50 \\
\hline & Sufficient & 45.40 & 57.25 \\
\hline & Medium & 40.95 & 23.75 \\
\hline & Low & 4.55 & 9.50 \\
\hline \multirow{4}{*}{ Iinguistic-communicative } & High & 4.55 & 4.75 \\
\hline & Sufficient & 45.40 & 43.00 \\
\hline & Medium & 36.40 & 38.00 \\
\hline & Low & 13.65 & 14.25 \\
\hline
\end{tabular}

According to the information-technological component of the readiness for professional socialization in both groups, about $9 \%$ of the respondents showed a high level. The largest share $-45.40 \%$ in EG and $57.25 \%$ in $\mathrm{KG}-$ were students with sufficient level of the development of the specified characteristic. A medium level of the development of this component was established in $40.95 \%$ of students of the experimental group and $23.75 \%$ of students of the control group. With regard to the low level of development of the information-technological component of readiness for professional socialization, the following picture is revealed: $4.55 \%$ of students in the experimental group and $9.50 \%$ in the control group.

According to the criterion of development of the linguistic-communicative component of readiness for professional socialization, the vast majority of students in both groups showed sufficient (experimental group $45.40 \%$; control group - 43\%) and medium level of the component development $(36.40 \%$ and $38 \%$, respectively). The low level of readiness for professional socialization was demonstrated by slightly more than one in ten participants (experimental group - 13.65\%; control group - 14.25\%); the proportion of students with high levels of readiness for professional socialization was the lowest $-4.55 \%$ in the experimental group and $4.75 \%$ in the control group.

\subsection{Tools for Collecting and Processing Statistics}

Quantitative methods, such as: evaluating and analysing results of the tests performed by students from both groups, questionnaires for students and teachers were used to accomplish the research objective. STATA Software (2019) was used to analyse the quantitative data. To analyse the responses of the focus group participants, we used the online tool - Text Analyzer - to determine the categorical framework of the study, following the recommendations of the OMNI (2019).

\section{Results}

After the mock-court in the Criminal Law and Civil Law courses, repeated assessments were made by the same components. Their results are shown in Table 3.

Comparison of indicators in Table 3 indicates that positive changes have occurred in all components of the readiness of law students of the experimental and control groups for professional socialization. The personalitymotivational component of students' readiness for professional socialization has undergone the greatest changes: the high levels of the development increased by $27 \%$ in the experimental group, while by almost $5 \%$ in the control group. The indicators of the other levels of development of this component in the experimental group decreased, and the indicators of the sufficient level increased $10 \%$ in the control group, the rest also decreased, but not so significantly.

We also see remarkable dynamics in the indicators of the personality-organizational component. Thus, in the experimental group, the indicators of high level of the development increased by $18 \%$, and sufficient - by $36 \%$. At the same time, indicators of both high and sufficient levels of development increased by $9.5 \%$ in the control group. It is clear that the indicators of the remaining levels of development decreased.

The analysis of the development of the operational-activity component of the readiness of the EG students for professional socialization shows an increase of indicators of high and sufficient level by $4.5 \%$ and $18 \%$, respectively. At the same time, no changes in the high-level indicators were identified in the control group $(0 \%)$, and indicators of the sufficient level increased by $9.5 \%$. 
Table-3. Comparative table of readiness of law students for professional socialization (post-experimental assessment).

\begin{tabular}{|c|c|c|c|}
\hline \multirow[t]{2}{*}{ Components of readiness } & \multirow[t]{2}{*}{ Levels of the development } & \multicolumn{2}{|c|}{ Post-experimental assessment } \\
\hline & & EG (\%) & CG (\%) \\
\hline \multirow{4}{*}{ Personality-organizational } & High & 22.70 & 14.25 \\
\hline & Sufficient & 49.95 & 19.00 \\
\hline & Medium & 18.25 & 47.75 \\
\hline & Low & 9.10 & 19.00 \\
\hline \multirow{4}{*}{ Operational-activity } & High & 9.10 & 4.75 \\
\hline & Sufficient & 36.30 & 28.50 \\
\hline & Medium & 40.95 & 52.25 \\
\hline & Low & 13.65 & 14.50 \\
\hline \multirow{4}{*}{ Cognitive-competence } & High & 9.10 & 4.75 \\
\hline & Sufficient & 31.70 & 24.00 \\
\hline & Medium & 40.95 & 42.75 \\
\hline & Low & 18.25 & 28.50 \\
\hline \multirow{4}{*}{ Personality-motivational } & High & 36.40 & 14.25 \\
\hline & Sufficient & 45.40 & 62.00 \\
\hline & Medium & 13.65 & 19.00 \\
\hline & Low & 4.55 & 4.75 \\
\hline \multirow{4}{*}{ Information-technological } & High & 13.65 & 9.50 \\
\hline & Sufficient & 54.50 & 62.00 \\
\hline & Medium & 31.85 & 23.75 \\
\hline & Low & --- & 4.75 \\
\hline \multirow{4}{*}{ Linguistic-communicative } & High & 9.10 & 9.50 \\
\hline & Sufficient & 63.55 & 52.25 \\
\hline & Medium & 18.25 & 28.75 \\
\hline & Low & 9.10 & 9.50 \\
\hline
\end{tabular}

A similar picture is observed regarding changes in the linguistic-communicative component. Thus, in the experimental group, high and sufficient levels increased by $4.5 \%$ and $18 \%$, respectively. In the control group, the increase in the high level was $4.5 \%$, and the sufficient level $-9 \%$. Changes in other indicators were not so significant.

In our opinion, the use of mock-court in the experimental group in the Criminal Law and Civil Law courses was the reason for the increase of the indicators of high level of students' readiness for professional socialization (cognitive-competence component) by $4.5 \%$ and indicators of a sufficient level of the specified component by $13 \%$. While traditional forms of submission and processing of educational material provided an increase in indicators of sufficient level by $12.5 \%$, the indicators of high level have not changed).

The worst dynamics of changes are recorded in the indicators of the information-technological component of students' readiness for professional socialization. In the experimental group, the increase in high level indicators was $4.5 \%$, sufficient level $-9 \%$. In the control group, the high level indicators did not change, and the sufficient level indicators increased by $5 \%$.

To confirm the experimental assumption about the effectiveness of the use of mock-court to increase the level of readiness of law students to professional socialization, mathematical and statistical processing of generalized results was performed using the Student's criterion. The value $(t=3.684)$ obtained during the processing reveals a significant difference in the changes in the experimental and control groups and, therefore, proves the reliability of the results obtained (table indicator $\mathrm{t}=2.10$; the obtained indicator $\mathrm{t}=3.684 ; 3.684>2.10$, so the experimental technique is more effective).

\subsection{Limitations of the Study}

The main limiting factors of this study are the short time span of the experimental phase ( 1 semester), a small number of simulations ( 2 in the Criminal Law course and 1 in the Civil Law course) developed and implemented in the educational process, uneven level of teachers' preparedness for the use of mock-court in the teaching process.

\section{Discussion}

During the implementation and reflection phase of the research, the results of the mock-court were also discussed with students and lecturers. Summarizing student responses as regards their impressions and evaluating their participation in mock-court allows arguing that most students find the experience gained to be extremely important, interesting and significant. The students noted that the simulations helped them better understand what knowledge or skills they lacked, how they worked, and what the importance of the "procedure" was, as well as the importance of learning how to interact in a team and effectively manage work and time.

Although positive changes are observed in all components of the readiness of law students of the experimental and control groups for professional socialization after conducting mock-court in the Criminal Law and Civil Law courses, we consider it necessary to pay attention to some interesting points of the conducted research. The most significant changes, as seen in our analysis of the results of post-experimental assessment and discussion with participants in mock-court, relate to the personality-motivational and personality-organizational components of students' readiness for professional socialization. And this has its logical explanations: the use of mock-court in the teaching process changes the role of students from passive "consumers" of general theoretical considerations and conclusions (of course, absolutely correct, but generated by other people) in lectures, or mostly observers, not participants in practical classes, seminars or practical training, to active participants in their own (not other people's) professional reality, albeit temporary and modelled. The level of self-organization increases because of the role change: each team member has his or her own task, and each, according to the students, has to "initiate" their own activity aimed at solving their personal tasks. 
Changes in the indicators of the operational-activity component of the readiness of law students for professional socialization in our study describe, above all, the increase in the ability to identify effective ways to accomplish tasks in students participating in the experiment. Undoubtedly, much of this success "belongs" to teachers who advised students at all stages of training and conducting mock-court (in both training courses).

Positive changes in the indicators of the linguistic-communicative component of the readiness of law students for professional socialization were less striking than we expected at the preparatory stage of our study. A possible explanation for this is that we have developed not only "roles" for mock-court but also lists of recommended language clichés and fixed expressions for these "roles", and therefore students did not have an urgent need to further develop terminological features of their "role".

It should be noted that the increase in the indicators of the cognitive-competence component of students' readiness for professional socialization in the application of mock-court simulations in the educational process and in the traditional delivery of educational material is quite comparable, with a modest advantage of simulation modelling technology. However, the dynamics of changes in the cognitive-competence component are somewhat slower (compared to the indicators of other components of students' readiness for professional socialization) due to several factors. First, the limiting factors of the study mentioned above, and second, the fact that the use of mockcourt in the educational process leads to the identification, a clear awareness of what knowledge the student lacks, and increasing students' ability to analyse and synthesize information, its critical understanding requires more time and experience in applying the knowledge acquired by students.

The moderate dynamics of changes in the indicators of the information-technological component of students' readiness for professional socialization are explained by the fact that students used their previously developed skills most often in preparation of their "roles" (the developed mock-court didn't provide for harsh conditions for using software which students didn't got used to), that is, the use of mock-court actually enhanced the already existing information and computer skills. Further development of mock-court in order to implement them in these and other training courses requires closer "collaboration" with lecturers of information and computer technologies to ensure greater effectiveness of purposeful influence on the development of information-technological component of students' readiness for professionalization.

Discussion and analysis of the results of the mock-court conducted in the Criminal Law and Civil Law training courses with lecturers revealed some lecturers' unwillingness to change the educational paradigm, not least because the learning process is purposeful, and the experimental use of simulations, in their opinion, has an uncertain and even unpredictable result. However, the lecturers noted that the experiment allowed them to see students from the other side, to change their perception of students who did not revealed themselves during lectures or traditional seminars. During mock-court, student activity got balanced and enhanced, since even passive members of the group were involved in the work, because the "game" required students to solve complex problems without leaving any possibility of being merely "passive observers". Therefore, using mock-court allows compensating the predominantly verbal nature of traditional teaching of legal disciplines and significant reducing students' passivity in learning. In addition, the positive experience of participating in mock-court reduces participants' anxiety.

\section{Conclusions}

Simulations are a certain version of reality, so the simulation technology is close to the role game, while being significantly different from it at the same time, because it aims at illustrative reproduction of certain phenomena and mechanisms. Therefore, simulation modelling technologies can be considered as a kind of tool that effectively helps lecturers to transfer, and students - to assimilate, the experience of their future professional activities. Students have the opportunity to study real-life behavioural models (based on models of professional-behavioural models of the representatives of different role positions). It can be argued that simulation modelling technologies contribute to students' adaptation to future professional activities.

It is established that the development and implementation of mock-court as interdisciplinary models in the professional training of law students has a strong potential to ensure the quality of teaching and improve students' readiness for their future professional activity. It has been found that the use of mock-court has the most significant influence on the formation and development of students' personal motivations, self-organization and planning skills, the ability to identify effective ways of accomplishing tasks, the ability to effectively use communication and linguistic skills. The study recorded a moderate impact of the use of mock-court in the Criminal Law and Civil Law courses on the formation and development of students' ability to analyse and synthesize information and critically understand it. In addition, the use of mock-court enhances students' motivation for learning; activates interpersonal interaction; creates conditions for revealing the student's potential; enable students to gain experience similar to the one they will pursue in the future; forces students to "nurture" certain personal skills needed in new organizational and educational settings (e.g., openness in communication and interaction, decision making, finding ways of self-assistance and assistance to other team members, responsibility, etc.).

The study illustrated that the use of mock-court promotes the transformation of students from the objects of learning into subjects of professionally-oriented learning activities, which increases their commitment to developing their own professional competitiveness.

We determine the prospects of further scientific research in the direction of development of interdisciplinary models and special methods of application of simulation modelling technologies for improving the quality of professional training of future specialists of different specialties in higher educational institutions.

\section{References}

ABA. (2014). Report and recommendations. Task Force on the Future of Legal Education. Retrieved from: http://www.americanbar.org/content/dam/aba/administrative/professional_responsibility/report_and_recommendations_of_aba _task_force.authcheckdam.pdf. [Accessed January 3, 2020].

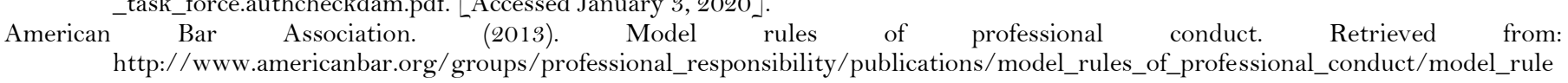
s_of_professional_conduct_table_of_contents.html. [Accessed January 3, 2020]. 
Arbetman, L., \& O'Brien, E. (2010). From classroom to courtroom: The mock trial. Retrieved from: http://www.19thcircuitcourt.state.il.us/bkshelf/resource/mt.htm. [Accessed January 3, 2020].

Artemjeva, O. A., \& Makeeva, M. N. (2007). The system of educational role-playing games of a professional orientation: monograph. Tambov: TSUT. Bandurka, O. M., \& Skakun, O. F. (2002). Legal deontology: A textbook. Kharkov: KhNUIA.

Bellotti, F., Berta, R., de Gloria, A., Ott, M., Arnab, S., de Freitas, S., \& Kiili, K. (2011). Designing serious games for education: from pedagogical principles to game mechanisms. Paper presented at the Proceedings of the 5th European Conference on Games-Based Learning, $20-21$ October. The National and Kapodistrian University of Athens, Greece.

Bodin, M., Marty, J., \& Carron, T. (2011). Specifying collaborative tools in game-based learning environments: Clues from the trenches. Paper presented at the Proceedings of the 5th European Conference on Games-Based Learning, 20-21 October. The National and Kapodistrian University of Athens, Greece.

Boise Mansilla, V., Gardner, H., \& Miller, W. C. (2000). On disciplinary lenses and interdisciplinary work, in: S. Wineburg, P. Grossman (Eds.), Interdisciplinary curriculum: Challenges of implementation (pp. 17-38). New York: Teachers College Press.

Boreychuk, A., \& Pelech, Y. (2016). Situational tasks in the disciplines "Civil process" and "Criminal process" for students of direction 6.030401 "Law". Rivne: NUPGP.

Boreychuk, A., \& Sakhno, V. (2015). Criminal and civil trial business games: Guidelines. Rivne: TM "Docent".

Burgess, T. F. (1995). Strategy support during a business game using an expert system, in: D. Saunders, J. Severn (Eds.), The International Simulation \& Gaming Research Yearbook: Simulations and Games for Strategy and Policy Planning (pp. 87-101). London: Kogan Page.

Butcher, A., Grimes, R., \& Parker, B. (2010). Law in action: Learning through scripted role plays. Retrieved from: http://www.ukcle.ac.uk/resources/roleplays/tutors/preparation.html. [Accessed January 3, 2020].

Crane, L. R. (1999). Interdisciplinary combined-degree and graduate law degree programs: History and trends. The John Marshall Law Review, 33, 47-80.

Dana, B., \& Sheps, C. G. (1968). Trends and issues in interprofessional education: Pride, prejudice, and progress. Journal of Education for Social Work, 4(2), 35-41.Available at: https://doi.org/10.1080/00220612.1968.10778686.

Faria, A., \& Dickinson, J. R. (1994). Simulation gaming for sales management training. Journal of Management Development, 13 (1), $47-59$.

Feshchuk, Y. V. (2009). Methods of development of spatial thinking of future technology teachers by means of computer graphics. Unpublished Doctoral Dissertation. National University of Life and Environmental Sciences of Ukraine. Kyiv.

Ivanchenko, E. A. (2005). Formation of professional mobility of future economists in the process of education in higher education institutions. Unpublished Doctoral Dissertation. K. D. Ushinskiy South Ukrainian State Pedagogical University, Odessa.

Jackson, J. R. (1959). Learning from experience in business decision games. California Management Review, 1(2), 92-107.Available at: https://doi.org/10.2307/41165351.

Jacob, W. J. (2015). Interdisciplinary trends in higher education. Palgrave Communications, 1(1), 1-5.Available at: https://doi.org/10.1057/palcomms.2015.1.

Jacobson, M. J., \& Wilensky, U. (2006). Complex systems in education: Scientific and educational importance and implications for the learning sciences. The Journal of the Learning Sciences, 15(1), 11-34.Available at: https://doi.org/10.1207/s15327809jls1501_4.

Kichuk, N. V. (2005). Game design as an interactive didactic technology training specialists. Science and Education, 3-4, 61-65.

Klein, J. T. (1990). Applying interdisciplinary models to design, planning, and policy-making. Knowledge, Technology and Policy, 3(4), 2955.Available at: $10.1007 / \mathrm{BFO} 2736654$.

Kodotchigova, M. (2002). Role play in teaching culture: Six quick steps for classroom implementation. Retrieved from: http://iteslj.org/Techniques/Kodotchigova-RolePlay.html [Accessed January 3, 2020 .

Kozakiewicz, J. (2008). Social work and law: A model approach to interdisciplinary education, practice, and community-based advocacy. Family Court Review, 46(4), 598-608.Available at: 10.1111/fcre.2008.46.issue-4.

Lutens, F. (1999). Organizational change and development. Organizational behaviour. Moscow: Tsyfra.

McCorcle, M. D. (1982). Critical issues in the functioning of interdisciplinary groups. Small Group Behavior, 13(3), 291-310.Available at: https://doi.org/10.1177/104649648201300302

Mironova, E. E. (2006). Collection of psychological tests. Part III. Manual. Minsk: Women's Institute ENVIL.

Morse, W. C., Nielsen-Pincus, M., Force, J. E., \& Wulfhorst, J. (2007). Bridges and barriers to developing and conducting interdisciplinary graduate-student team research. Ecology and Society, 12(2), 1-14.Available at: https://doi.org/10.5751/es-02082-120208.

Nancarrow, S. A., Booth, A., Ariss, S., Smith, T., Enderby, P., \& Roots, A. (2013). Ten principles of good interdisciplinary team work. Human Resources for Health, $11(1), 19$.Available at: 10.1186/1478-4491-11-19.

Newell, W. H. (2007). Decision making in interdisciplinary studies, in: G. Morcol (Ed.), Handbook of decision making (pp. 245-265). New York: CRC

NHBA's Law Related Education Programm. (2017). Mock trial competition handbook. Retrieved from: https://www.nhbar.org/wpcontent/uploads/2017/11/LRE-MockTrial-CompetitionHandbook.pdf. [Accessed January 3, 2020].

OMNI. (2019). Toolkit for conducting focus groups. Retrieved from: https://www.nyla.org/max/userfiles/Documents/D._Focus_Group_Toolkit.pdf. [Accessed January 3, 2020].

Pometun, O. I. (2007). Encyclopedia of online learning. Kyiv: ASK.

Popova, G. V. (1997). Professional communication competence of a police officer. Unpublished Doctoral Dissertation. University of Internal Affairs. Kharkiv.

Roehler, L., Fear, K., \& Herrmann, B. A. (1998). Connecting and creating for learning: Integrating subject matter across the curriculum and the school. Educational Psychology Review, 10(2), 201-225.

Sisk, D. A. (1995). Simulation games as training tools, in: S. M. Fowler, M.G. Mumford (Eds.), Intercultural sourcebook: Cross-cultural training methods (pp. 81-92). Yarmouth, MN: Intercultural Press.

STATA Software. (2019). Retrieved from: https://www.stata.com/. [Accessed January 3, 2020].

Stone, A. R. (1969). The interdisciplinary research team. The Journal of Applied Behavioral Science, 5(3), 351-365.

Taylor, S. (2006). Educating future practitioners of social work and law: Exploring the origins of inter-professional misunderstanding. Children and Youth Services Review, 28(6), 638-653.Available at: https://doi.org/10.1016/j.childyouth.2005.06.006.

The Vincent J. Apruzzese High School. (2019). Mock trial competition: High school workbook. Retrieved from: https://njsbf.org/wpcontent/uploads/2019/09/MT-2019-case.pdf. [Accessed January 3, 2020].

Tynjälä, P., Slotte, V., Nieminen, J. T., Lonka, K., \& Olkinuora, E. (2006). From university to working life: graduates' workplace skills in practice, in: P. Tynjälä, J. Välimaa, G. Boulton-Lewis (Eds.), Higher education and working life: Collaborations, confrontations and challenges (pp. 77-88). Amsterdam: Elsevier Earli.

Weinberg, A., \& Harding, C. (2004). Interdisciplinary teaching and collaboration in higher education: A concept whose time has come. Washington University Journal of Law $\Xi^{\circ}$ Policy, 14, 15-48.

Weinstein, J. (1999). Coming of age: Recognizing the importance of interdisciplinary education in law practice. Washington Law Review, 74, 319-366. 